\title{
El antifundamentalismo radical del neodualismo postanalítico. A través de von Wright y Apel.
}

\author{
The radical anti-fundamentalism \\ of post-analytic neo-dualism. \\ Through von Wright and Apel
}

\author{
CARLOS ORTIZ DE LANDÁZURI. \\ Universidad de Navarra
}

Recibido: 19-VIII-2013 Aprobado: 8-XII-2013

\begin{abstract}
RESUMEN
El neodualismo postanalítico atribuyó a Russell, el primer Wittgenstein y Popper una actitud radicalmente anti-fundamentalista, con posterioridad a la teoría de los juegos del lenguaje del segundo Wittgenstein, debido a tres motivos, al menos según Von Wright y Apel, a saber: la fundamentación dogmática inductivista del positivismo lógico en los dos primeros casos; las sucesivas refundaciones meramente hipotéticas del racionalismo crítico en Popper; y, finalmente, la fundamentación explicativo-comprensiva preconizada de un modo meliorista por el pragmatismo semántico en aquel último caso. Pero a pesar de este acuerdo básico, von Wright y Apel discreparon acerca del sentido meramente pragmático, o más bien pragmáticotranscendental que, a pesar de todo, se debería seguir otorgando a la noción de fundamentación en los seguidores de estas nuevas tendencias del neodualismo postanalítico.
\end{abstract}

PALABRAS CLAVE

SEMIÓTICA, HEURÍSTICA, FALSACIONISMO, ANÁLISIS, NUEVO DUALISMO.

\section{ABSTRACT}

Subsequently to the theory of the games of language by the latest Wittgenstein, post-analytic neo-dualism attributed a radically anti-fundamentalistic attitude to Russell, the first Wittgens-

(C) Contrastes. Revista Internacional de Filosofía, vol. XX-No 1 (2015), pp. 29-45. ISSN: 1136-4076

Departamento de Filosofía, Universidad de Málaga, Facultad de Filosofía y Letras Campus de Teatinos, E-29071 Málaga (España) 
tein and Popper, based on three reasons, at least according to von Wright and Apel: The inductive dogmatic foundation of the logical positivism of the two first cases; the permanent hypothetical re-foundation of the critical rationalism of Popper; and, finally, the explanatory-understanding foundation defended in a melioristic way by the semantic pragmatism of the latter. But notwithstanding this basic agreement, von Wright and Apel disagreed about the merely pragmatic, or rather pragmatic-transcendental sense that, in spite of everything, should be awarded to the notion of foundation in the followers of these new tendencies of post-analytic neo-dualism.

KEYWORDS

SEMIOTICS, HEURISTICS, FALSIFICATIONISM, ANALYSIS, NEO-DUALISM.

\section{LA REVISIÓN DEL LUGAR DE RUSSELL Y EL PRIMER WiTTGENSTEIN EN EL DEBATE EXPLICACIÓN-COMPRESIÓN, 40 AÑOS DESPUÉS.}

La publicación de Explicación y Comprensión en 1971 - EU, EC -1, por parte de G. H. von Wright, significó un giro radical en las interpretaciones tradicionales de la filosofía analítica, permitiendo a su vez justificar la génesis del «nuevo dualismo» postanalítico posterior al segundo Wittgenstein. En su opinión, ya el primer Wittgenstein habría roto con dos supuestos del positivismo lógico, con anterioridad a la ulterior ruptura del segundo Wittgenstein, a saber ${ }^{2}$ :

1) Revisar críticamente la justificación explicativo-causal de tipo inductivo-probabilista, como la postulada por Russell, atribuyéndole una justificación meramente psicológica, sin otorgarle un valor propiamente lógico ${ }^{3}$;

2) la extrapolación del positivismo lógico a las ciencias de la conducta y al resto de las ciencias sociales, sin aplicarlo exclusivamente a la ciencia físiconatural, como seguía proponiendo Russell. Máxime cuando Hempel y el resto de los participantes en el debate reconocieron la imposibilidad de justificar de un modo inductivo el método explicativo-causal, salvo que se subsumiera en un modelo nomológico-deductivo o de cobertura legal, cosa que Russell nunca habría admitido ${ }^{4}$.

En efecto, el propio Russell reconocía la dificultad de justificar un salto inductivo desde lo particular a lo universal mediante este tipo de explicaciones

1 Wright, G. H. von; Explanation and Understanding, Cornell University, Ithaca, 1971; Explicación y comprensión, Alianza, Madrid, 1987.

2 Ortiz de Landázuri, C.; 'La doble génesis semiótica y heurística del neodualismo postanalítico. (A través del primer Wittgenstein y Popper, según von Wright y Apel)', Contrastes, Málaga, 2011.

3 Russell, B.; Toward the "Principles of Mathematics", 1900-02, Routledge, London, 1993.

4 Horn, P. R.; Gadamer and Wittgenstein on the Unity of Language: Reality and Discourse Without Metaphysics, Ashgate, Hampshire, 2005. 
causales de naturaleza nomológica deductiva. En ese caso el positivismo lógico habría tenido que postular un mimetismo o isomosfismo en sí mismo dogmático entre los hechos y las leyes, o entre las observaciones y los conceptos, sin poder aducir una justificación heurística proporcionada. De ahí que la pretendida justificación inductiva del modelo nomológico deductivo o de cobertura legal acabó adquiriendo carácter racionalista dogmático, por mucho que Russell pretendiera lo contrario 5 .

Sin embargo el primer Wittgenstein en el «Tractatus» reinterpretó el problema de la inducción, como si se tratase de un problema estrictamente psicológico que ya no permitiría justificar las numerosas ambigüedades e imprecisiones del uso vulgar del lenguaje. En cambio, sólo la reconstrucción lógica de un lenguaje ideal perfecto permitiría justificar un uso clarificador del lenguaje, incluidos el uso correcto de los conectivos lógicos. Además, el primer Wittgenstein habría propuesto confirmar las mayores virtualidades del positivismo lógico mediante la aplicación del modelo nomológico deductivo o de cobertura legal a las ciencias humanas y sociales o de la conducta, incluida la propia psicología 6 .

Por su parte Karl Otto Apel en 1979 también revisó las propuestas de von Wright en una monografía dedicada al tema, El debate explicación/comprensión desde un punto de vista pragmático-transcendental (1979) -EVKTPS ${ }^{7}$. En general Apel comparte las propuestas de von Wright, aunque matizando su propuesta: a su modo de ver el primer Wittgenstein otorgó al modelo nomológico deductivo o de cobertura legal una amplitud todavía mucho mayor, concibiéndolo como un requisito de cualquier forma de control experimental científico de la consabida articulación entre teoría y práctica, entre el lenguaje y la experiencia, entre los conceptos y la observación. En este sentido le habría otorgado un alcance pragmático-transcendental que antes no tenía, en

5 A este respecto von Wright afirma: «Ha sido uno de las principales tesis de este libro la de que se deben disociar, como absolutamente distintas, la causalidad en el ámbito de la naturaleza y (...) lo que ocurre en la acción intencional». Wright, G. H. von; EU, p. 160. Cf. Wuchterl, K.; Handbuch der analytischen Philosophie und Grundlagenforschung. Von Frege zu Wittgenstein, Haupt, Bern, 2002.

6 Por eso afirmará Wright: «Retrospectivamente casi parece una ironía del destino que la formulación más completa y lúcida de la teoría positivista sobre la explicación llegara a establecerse a propósito de la materia para la que, obviamente, la teoría se haya peor dispuesta, a saber, la historia. Aun cuando es posible que, precisamente por esa razón, el trabajo de Hempel provocara discusiones y controversias sin cuento». Wright, G. H. von; EC, p. 29-30. Cf. Baker, G. P.; Hacker, P. M. S.; Wittgenstein Meaning and Understanding. Essays on the Philosophical Investigations I, Blackwell, Oxford, 2004.

7 Cf. Apel, K. O.; Die Erklären:Verstehen-Kontroverse in transzendentalpragmatischer Sicht- EVKTPS-, Suhrkamp, Frankfurt, 1979. 
la medida que pretendió aplicar el lenguaje ideal de la lógica a toda forma de saber científico ${ }^{8}$.

Además, Apel opina que a partir del primer Wittgenstein, el positivismo lógico se volvió a cuestionar un tipo de problemas similares a los que ya se planteó la filosofía alemana neokantiana y neohegeliana posterior en el siglo XIX. Especialmente cuando numerosos post-hegelianos llevaron a cabo una revisión de los planteamientos estrictamente positivistas de Comte y Mill, con el claro propósito de reeditar unas nuevas formas de positivismo historicista abierto a las ciencias humanas. Hasta el punto que Apel opina que algo similar habría acabado ocurriendo con algunos postwittgenstenianos, cuando propugnen una vuelta a unas posturas posthegelianas similares a las de Dilthey o Max Weber, como sucedió en los casos de Taylor o McDowell9.

En todos estos casos Apel defiende una tesis bastante original: en su opinión, las increíbles virtualidades heurísticas asignadas por el primer Wittgenstein al positivismo lógico, ya sea en su versión fisicalista o historicista, no dependen tanto del uso dogmático que se hace de un método inductivo, como del recurso a un modelo nomológico deductivo, de cobertura legal o de fundamentación entre teoría y práctica, llegándose en todos los casos a una conclusión bastante similar: la necesidad de extrapolar el recurso a este modelo nomológico deductivo o de cobertura legal estrictamente positivista lógico a toda forma de saber, a pesar de tener que remitirse a un tipo de fundamentación en sí mismo dogmático, como al menos sucedió en Hempel, o antes en Russell y al primer Wittgenstein, o incluso en Comte o Mill ${ }^{10}$.

\section{LA REVISIÓN DE POPPER DESDE EL DEBATE EXPLICACIÓN-COMPRENSIÓN, 40 AÑOS DESPUÉS.}

La reconstrucción que Von Wright y Appel proponen del debate entre explicación y comprensión también les obligó a revisar las propuestas del racionalismo crítico de Karl Popper. De hecho Popper ya en los tiempos de Viena, en La Lógica de la Investigación Científica (1933) - LF¹1 -, propuso dar un vuelco similar en el modo inductivista como Russell justificó el saber científico, para sustituirlo por otro de tipo falsacionista. Pero por razones similares también rechazó el uso positivista lógico o racionalista dogmático que

8 Smilg Vidal, N.; Consenso, evidencia y solidaridad. La teoría de la verdad de Karl-Otto Apel, Comares, Granada, 2000.

9 McGinn, M.; Elucidating the 'Tractatus'. Wittgenstein's Early Philosophy of Logic and Language, Clarendon, Oxford University, Oxford, 2006.

10 Ostrow, M. B.; Wittgenstein's Tractatus. A Dialectical Interpretation, Cambridge University, Cambridge, 2002.

11 Popper, K. R.; Logik der Forschung, J. C. B. Mohr (Paul Siebeck), Tübingen, 1934 $\left(1^{\mathrm{a}}\right), 1989$. 
Russell y el primer Wittgenstein hacían del modelo nomológico-deductivo o de cobertura legal para proponer en su lugar otro de tipo racionalista crítico, aunque no llegara a apreciar las posturas tan distintas de ambos respecto al problema de la inducción, al menos según von Wright y Apel. A este respecto von Wright resalta como Popper habría rechazado el inductivismo de Russell y el primer Wittgenstein, sin tampoco hacer una especial distinción entre ellos, sacando dos consecuencias ${ }^{12}$ :

1) Proponer el método de la falsación como criterio de demarcación de la actividad científica en sustitución del método de la inducción, completándolo con una interpretación racionalista crítica del modelo nomológico deductivo o de cobertura legal en vez de la anterior interpretación positivista lógica y racionalista dogmática ${ }^{13}$;

2) Introducir una clara separación entre el contexto y la lógica de la justificación respecto del contexto y la psicología de descubrimiento, sin tampoco hacer depender el posterior uso del lenguaje ordinario de un seguimiento rutinario de la inducción, cuando también el uso del lenguaje científico debe entrar a formar parte de contexto de la justificación y se debe regular mediante una lógica de la falsación ${ }^{14}$.

En este sentido Popper considera que el primer Wittgenstein siguió justificando este tipo de procesos semióticos de formación del lenguaje cotidiano a través de una psicología de tipo inductivo que incrementa aún más la crisis de fundamentos provocada por Russell. Hasta el punto que, según Popper, los lenguajes vulgares que el primer Wittgenstein denunció por haber acabado fomentado una mera justificación psicológica de las descripciones de los hechos de la experiencia podrían acabar siendo aún más dogmáticos, especialmente si también se sigue regulando este saber mediante un uso positivista lógico del modelo nomológico deductivo. En cualquier caso, la estrategia heurística seguida por el «Tractatus» del primer Wittgenstein no acaba de precisar las ventajas que se derivan de atribuir a la lógica en vez de a la psicología la clarificación del uso correcto del lenguaje, cuando de hecho ambas hacen un uso positivista lógico igualmente dogmático del modelo nomológico deductivo. En efecto, si Wittgenstein denuncia a la psicología por seguir haciendo un mal uso del método inductivo y por fomentar una retórica verbalista vacía de contenido empírico, también habría que decir lo mismo respecto de la lógica. Especialmente cuando se comprueba la engañosa suficiencia con que Wittgenstein acaba concibiendo

12 Cf. Cf. Ter-Hark, M.; Popper, Otto Selz and the Rise of Evolutionary Epistemology, Cambridge University, Cambridge, 2004.

13 Cf. Wright, G. H. von; EU, p. VIII. Cf. Popper, K. R.; Los dos problemas fundamentales de la epistemología. Basado en los manuscritos de los años 1930-1933, Tecnos, Madrid, 2007.

14 Cf. Apel, K. O.; EVKTPS, p. 120. Cf. Shook, J. R.; Margolis, J. (eds); A Companion to Pragmatism, Blackwell, Oxford, 2006. 
la inducción como un problema superfluo, cuando era justamente la asignatura pendiente que al positivismo lógico le quedaba por superar ${ }^{15}$.

Popper interpreta así el «Tractatus» en continuidad con las propuestas metodológicas inductivistas tan estrictas formuladas por el positivismo lógico de Bertrand Russell, sin otorgar demasiada importancia al olvido sistemático que en el «Tractatus» se hace del problema de la inducción. En este sentido Popper no acaba de advertir la creciente sima que para entonces se había abierto entre las respectivas propuestas de Russell y del primer Wittgenstein. De hecho ambos situaban sus correspondientes proyectos programáticos en niveles muy distintos de justificación heurística: Russell se preocupa preferentemente de la ciencia y de la investigación experimental mientras que el primer Wittgenstein del lenguaje científico y de la comunicación humana ${ }^{16}$.

Evidentemente para von Wright las diferencias existentes entre el primer Wittgenstein y Popper acabaron siendo mayores que las que anteriormente el primero había mantenido con Russell. En efecto, el primer Wittgenstein nunca habría pretendido resolver el problema de la intercomunicación científica por recurso a un principio de falsación o refutación de hipótesis, al modo popperiano. En efecto, según el primer Wittgenstein, de aceptar esta posibilidad habría que presuponer que las relaciones semióticas o meramente verbales pudieran a su vez ser objeto de una explicación causal similar a la usada por el resto de las ciencias naturales o factuales, por recurso a un método preferentemente inductivo, cuando más bien ocurre lo contrario: el uso del lenguaje científico ahora se concibe como una condición de posibilidad y de sentido que debe ser resuelta mediante un modelo nomológico deductivo o de cobertura legal según una lógica axiomática totalmente independiente de la experiencia ${ }^{17}$.

En este sentido el primer Wittgenstein considera que, ni la inducción, como pretendía Russell, ni la falsación, como pretendía Popper, pueden explicar la génesis del lenguaje científico. En su lugar se debería justificar más bien mediante un uso positivista lógico de un modelo nomológico deductivo o de cobertura legal, que fuera capaz de justificar la posibilidad de un lenguaje ideal; es decir, que permitiera justificar un pleno isomorfismo respecto de los demás interlocutores y a la vez con la experiencia. Sólo después, en la fase de la

15 A este respecto von Wright afirma: «El test definitivo para juzgar sobre la validez universal de la teoría de la explicación por subsunción es la de si puede hacerse cargo cabalmente de la explicación de las acciones. (...) Este frente de oposición viene representado por los filósofos analíticos que se ocupan de la metodología de la historia». Wright, G. H. von; EU, p. 23. Elster, J.; Reason and Rationality, Princeton University, Princeton, 2008.

16 Cf. Cf. Schulte, J.; Ludwig Wittgenstein, Suhrkamp, Frankfurt, 2005.

17 Russell, B.; Our Knowledge of External World: as a field for Scientific Method in Philosophy, Blackwell, Oxford, 1998. 
aplicación, se podría tratar de corroborar su uso correcto mediante un método inductivo, como el de Russell o hipotético-falsacionista, como el de Popper ${ }^{18}$.

De ahí que el lenguaje cientifico para el primer Wittgenstein tenga que justificarse mediante un procedimiento analítico, axiomático y estrictamente formal de comprensión recíproca, según los cánones previamente fijados a su vez por el positivismo lógico. Pero en ningún caso la construcción de este lenguaje ideal de carácter isomórfico respecto de los demás interlocutores y con la experiencia se podrá justificar mediante el seguimiento compartido de un método estrictamente experimental, ya sea de tipo inductivo o falsacionista, como pretendían respectivamente Russell y Popper. Ni tampoco se podrá alcanzar mediante un uso racionalista crítico y en sí mismo falsacionista de un modelo nomológico deductivo o de cobertura legal, donde el objetivo prioritario es refutar las pocas o muchas estructuras lingüísticas disponibles en cada caso, sin poder garantizar tampoco una reposición verdaderamente proporcionada, dejando todo al albur de los acontecimientos ${ }^{19}$.

En efecto, según el primer Wittgenstein, resulta un sinsentido tratar de fomentar programáticamente una autodestrucción sistemática del principal medio de comunicación todavía disponible, pasando del todo, o más bien del poco, a la nada, o desde un lenguaje de mínimos a una ausencia total del lenguaje, cuando se debía procurar justamente lo contrario, a saber: otorgar a cualquier indagación heurística verdaderamente compartida la capacidad de dotarse de las mejores herramientas semióticas de intercomunicación posible, tratando de lograr a su vez una creciente conmensuración recíproca entre el método y su respectivo objeto, a pesar de saber de antemano que el isomorfismo encontrado nunca será perfecto, como de un modo esquemático al menos se intentó en el «Tractatus» ${ }^{20}$.

De todos modos Apel por su parte añade una observación importante: en su opinión, la lógica de la investigación científica popperiana llevó a cabo una radicalización antifundamemtalista, no tanto debido al recurso que en su caso se hace a un método de falsación, sino a una exigencia posterior, a saber: la necesidad de fomentar un estado de permanente refundación revisionista que ahora viene exigido por la posterior subsunción del método de la falsación en un modelo nomológico deductivo o de cobertura legal de carácter racionalista crítico que exige sustituir las antiguas hipótesis por otras igualmente revisables. Sólo así sería posible justificar un antifundamentalismo cada vez más radicali-

18 McGuinness, B.; Young Ludwig. Wittgenstein's Life 1889-1921, Oxford University, Oxford, 2005.

19 Richter, D.; Wittgenstein at His World, Continuum, London, 2005.

20 Cf. Wittgenstein, L.; TLP, 3.263; Cf. Ortiz de Landázuri, C.; 'La autodestrucción de la crítica del sentido en Wittgenstein y Heidegger. (A través de Karl-Otto Apel)', Anuario Filosófico, 2000/3, p. 833-859. 
zado donde basta un simple fracaso en un experimento para que se tenga que cuestionar todo el conjunto de leyes de las que depende esa descripción sin ninguna limitación, como ahora propugna Popper. Con el agravante de que estas propuestas ahora también se extrapolan para las ciencias de la conducta y la propia historia, como también sucederá en las metodologías científicas de Feyerabend, Lakatos y Bartley ${ }^{21}$.

A este respecto Apel hace notar como la postura de Popper desde la época de Viena fue muy distinta de la propuesta por el primer Wittgenstein en el «Tractatus». En efecto, Popper no sólo postuló una substitución del uso dogmático del método de la inducción por el de la falsación o refutación de hipótesis, sino que además postuló la sustitución de uso positivista lógico de un modelo nomológico deductivo o de cobertura legal por otro de tipo racionalista crítico o meramente hipotético-refutador, donde se fomenta una actitud igualmente antifundamentalista, tanto respecto a la investigación científica como respecto del uso del lenguaje ${ }^{22}$.

En efecto, Popper no sólo admitió la posible refutación de las hipótesis científicas, sino que radicalizó aún más la crítica al engreído verbalismo logicista presente aún en el «Tractatus», así como a toda forma de historicismo positivista, como puso de manifiesto en La miseria del historicismo. En todos estos casos consideró que tanto la investigación científica como el uso del lenguaje, debían someterse al seguimiento de un método de falsación, así como a un uso racionalista crítico de un modelo nomológico deductivo o de cobertura legal, en permanente estado de refundamentación en sí mismas hipotética, sin hacer ningún tipo de distinción entre el procedimiento a seguir en estos dos tipos de supuestos ${ }^{23}$.

21 Y en este sentido Apel afirma: «Se puso así manifiesto como la constitución social de los datos o de los hechos (en el marco del así llamado contexto del descubrimiento popperiano) está a su vez mediada (..) por su expresión conceptual lingüística; y, por teorías» . Apel, K. O.; EVKTPS, p. 120. Cf, Hutto, D. D.; Wittgenstein and the End of Philosophy. Neither Theory Nor Therapy, Palgrave, Houndmills, 2003.

22 Cf. Popper, K. R.; LF, p. 23; LSD, p. 51; LIC, p. 50. Cf. Edmonds, D. J.; Eidinow, J. A.; Wittgenstein's Poker. The History of Ten-minute Argument Between two Great Philosophers, Faber and Faber, London, 2001.

23 A este respecto Apel afirma: «La «explicación causal» de un suceso, como ya he descrito, se expresa a través de una proposición que, según Popper, se justifica deductivamente a partir de leyes y otras condiciones marginales. En esta formulación se prejuzga la equiparación del «contexto de la justificación» (popperiano) con la elaboración de un conocimiento sintético relativo al descubrimiento de las causas de un inesperado fenómenos de la experiencia mediante una operación con un fundamento lógico muy preciso, que a su vez permitirá deducir a modo de pronóstico unas determinada consecuencias mediante una explicación causal de tipo legal (o mediante una simple generalización de los correspondientes síntomas)». APEL, K. O.; EVKTPS, p. 83. Cf. Aleksandrowicz, D.; Russ, H. G. (Hrsg.); Realismus, Disziplim, Interdisziplinarität 
Popper atribuyó así a la mente humana una ilimitada capacidad de invención heurística para justificar así la progresiva aparición de distintos niveles teóricos de intersubjetividad aún más compartida, como son la leyes, la hipótesis, los conceptos, las funciones, los principios o los elementos, o como ahora también sucede con el propio uso compartido de convenciones, incluidas las diversas formas de lenguaje científico. Sin embargo tuvo un precio esta subsunción racionalista crítica de todos los métodos científicos bajo un uso hipotético-refutador de un modelo nomológico deductivo o de cobertura legal, a saber: la atribución en todos los casos del mimo grado de falibidad endémica, sin apreciar las diferencias existentes entre los procesos de explicación causal y de comprensión recíproca, como si los procesos físico-naturales se pudieran regular del mismo modo que las convenciones sociales. En todos los casos la falsación de una hipótesis físico natural debe ser seguida de un proceso ininterrumpido de sucesivas refundaciones igualmente falibles, sin poder poner fin a este proceso. Es decir, sin poder postular un posible acuerdo a largo plazo entre las necesarias predeterminaciones legales de la naturaleza y las libres posdeterminaciones ulteriores alcanzadas a lo largo de la historia que exigen considerar refutado lo que anteriormente se tenía por verificado ${ }^{24}$.

\section{WRIGHT, 1971: \\ El lugar de Russell, Popper y el Primer Wittgenstein \\ EN EL DEBATE EXPLICACIÓN-COMPRENSIÓN \\ DESDE UN PUNTO DE VISTA RETROSPECTIVO.}

Von Wright en «Explicación y comprensión» (1971) llevó a cabo una reconstrucción de este debate casi cuarenta años después, cuando ya todas las posturas estaban muy consolidadas. Su propósito fue encontrar una vía media entre las propuestas de Russell, el primer Wittgenstein y Popper, cuando ya se sabía que la posterior teoría de los juegos del lenguaje del segundo Wittgenstein tampoco había acabado de resolver el problema, estando todas las posibilidades aún abiertas ${ }^{25}$. En este sentido von Wright y Apel se distanciaron de la excesiva

(Zur Karl R. Popper), Rodopi, Amsterdam, 2001.

24 A este respecto von Wright afirma: «Ha sido uno de las principales tesis de este libro la de que se deben disociar, como absolutamente distintas, la causalidad en el ámbito de la naturaleza y la acción humana, sea individual o colectiva. (...) Es útil distinguir dos tipos de determinismo, (...) que pueden ser llamados predeterminación y postdeterminación respectivamente. La inteligibilidad de la historia es un determinismo ex post facto». Wright, G. H. von; EU, p. 160-161. Cf. Martínez Solano, J. F.; El problema de la verdad en K.R. Popper. Reconstrucción histórico-sistemática, Netbiblo, Oviedo, 2005.

25 Glock, H-J.; Hyman, J. (eds.); Wittgenstein and Analytic Philosophy. Essays for P. M. S. Hacker, Oxford University, Oxford, 2009. 
confianza que Russell y el primer Wittgenstein habían seguido fomentando el seguimiento positivista lógico de un modelo nomológico deductivo o de cobertura legal, cuando mediante este procedimiento tampoco es posible abordar el problema de la inducción por volverse una cuestión en sí misma irrelevante. Pero de igual modo también rechazaron el excesivo escepticismo semiótico con que Popper fomentó el uso racionalista crítico del modelo nomológico deductivo o de cobertura legal con un único fin: fomentar un proceso se sucesivas refundamentaciones en el uso heurístico y semiótico de la ciencia y de las respectivas formas de lenguaje. Se abordan ambos supuestos como si se tratara de justificar una hipótesis experimental similar a las demás, cuando se les atribuye un carácter natural y convencional específicamente distinto ${ }^{26}$.

En cualquier caso von Wright reconstruyó el debate explicación-comprensión desde un punto de vista simplemente pragmático, muy distinto al punto de vista pragmático-transcendental de Apel. Logró así separar al menos tres modelos nomológicos deductivos o de cobertura legal diferenciados, a saber ${ }^{27}$ :

1) El seguimiento de una estrategia positivista lógica para dilucidar el uso correcto del lenguaje científico mediante la aplicación de un modelo nomológico deductivo o de cobertura legal, a pesar de adolecer de un carácter inductivamente dogmático, al modo propuesto por Russell y el primer Wittgenstein en el «Tractatus» (1923). En efecto, según von Wright, sólo así el análisis de lenguaje habría podido clarificar aquellos elementos lógicos de tipo verbal que permiten describir la experiencia por parte de la ciencia natural, justificando los distintos elementos moleculares, leyes y teorías mediante una simple definición, a partir de la previa formulación de simples proposiciones atómicas. De este modo la metodología científica habría podido denunciar los numerosos malentendidos generados por el mal uso del lenguaje cuando se otorga a una explicación cientifica un falso sentido legal, otorgando al problema de la inducción un lugar muy secundario, a diferencia de Russell ${ }^{28}$.

2) El seguimiento de una estrategia racionalista-crítica que permite garantizar el buen uso del lenguaje científico mediante un uso falsacionista aún más estricto del modelo nomológico deductivo o de cobertura legal, a pesar de

26 Wernecke, J.; Handeln und Bedeutung. L. Wittgenstein, Ch. S. Peirce und M. Heidegger zu einer Propädeutik einer hermeneutischen Pragmatik, Duncker und Humblot, Berlin, 2007.

27 Russell, B.; Theory of Knowledge, the 1913 Manuscript, Allen and Unwin, London, 1984.

28 A este respecto von Wright afirma: «El positivismo (.... evita) dar razón de los hechos en términos de intenciones, fines, propósitos, y o bien las rechaza como acientíficas, o bien tiende a mostrar que, una vez debidamente depuradas de restos «animistas» o «vitalistas», vienen a transformarse en explicaciones causales». Wright, G. H. von; EU, p. 4. Cf. Mulhgall, S.; Wittgenstein's Private Language. Grammar, Nonsense, and Imagination in Philosophical Investigations, \&\& 243-315, Oxford University, Oxford, 2006. 
adolecer de un carácter hipotético en sí mismo relativista, al modo defendido por Popper en «La lógica de la investigación cientifica» (1933). Von Wright considera en cualquier caso que la propuesta de Popper tuvo una ventaja indudable, a saber: consiguió localizar el modelo nomológico deductivo (DN) o de cobertura legal, según el cual, una ley científica sólo será correctamente comprendida cuando se reconozca su carácter falsable, así como su posible sustitución por otra de rango legal igual o superior, que a su vez también se debería someter de nuevo al consiguiente proceso de falsación o refutación de hipótesis en sí mismas revisables, sin poder ya admitir excepciones al respecto. Además, según von Wright, Popper habría fomentado un uso estrictamente pragmático de este modelo nomológico deductivo o de cobertura legal, como estrategia a seguir para elegir la hipótesis más correcta, sin que la refutación de un solo hecho exigiera la revisión de todo el sistema de leyes de las que depende, como después pretenderá Apel ${ }^{29}$.

3) El seguimiento de una estrategia neodualista de un modelo explicativocomprensivo, al modo defendido por la filosofía del lenguaje ordinario del segundo Wittgenstein en «Investigaciones filosóficas» $(1953)^{30} \mathrm{y}$ en «Cultura y valor» $(1980)^{31}$. Fue entonces cuando el segundo Wittgenstein aplicó al análisis de la experiencia y de los convencionalismos sociales una peculiar teoría de los juegos del lenguaje, que le permitió caracterizar desde un punto de vista heurístico las distintas ciencias, incluidas las ciencias de la conducta y sociales o de la historia, así como las distintas formas de experiencia. Se pudieron distinguir así los respectivos procesos de explicación experimental y de comprensión recíproca en el uso compartido de un mismo lenguaje científico, atribuyéndoles en cada caso procedimientos heurísticos y semióticos de justificación específicamente distintos, cosa que no había logrado Popper, ni tampoco el primer Wittgenstein. Pero a pesar de este indudable acierto, el segundo Wittgenstein tampoco pudo superar una dificultad evidente. Sólo pudo evitar el recurso a una justificación meramente convencional y en sí misma dogmática mediante un meliorismo a largo plazo cada vez más utópico y abstracto que siempre presupone, pero Huinca justifica. ${ }^{32}$

29 Cf. Wright, G. H. von; EU, 14. Cf. Lewis, P. (ed); Wittgenstein, Aesthetics and Philosophy, Ashgate, Hampshire, 2002.

30 Wittgenstein, L.; Philosophical Investigations, Blackwell, Oxford, 1998.

31 Wittgenstein, L.; Culture and Values, Routledge, London, 1993.

32 Potter, M; Ricketts, T. (eds.); The Cambridge Companion to Frege, Cambridge University Press, Cambridge, 2010. 


\section{APEL, 1979: EL TRASFONDO PRAGMÁTICO-TRANSCENDENTAL DEL DEBATE EXPLICACIÓN-COMPRENSIÓN.}

Por su parte Apel, en La controversia explicación-comprensión de 1979 - EVKTPS ${ }^{33}$-, también adoptó un punto de vista pragmático-transcendental aún más abierto, al modo como anteriormente en 1973 ya había propuesto en Transformación de la filosofía ${ }^{34}$. Sólo así fue posible llevar a cabo una revisión aún más autocrítica de este doble proceso de indagación heurística y de comunicación semiótica que habría sido iniciado por Russell, el primer Wittgenstein y Popper. De todos modos posteriormente la teoría de los juegos del lenguaje habría radicalizado aún más este tipo de propuestas, aunque sin tampoco conseguir fundamentarlas de un modo pragmático-transcendental plenamente satisfactorio, al modo como propuso Peirce. En este sentido Apel opina que la reconstrucción del debate explicación y comprensión debería comenzar proponiendo una descripción de las tres posturas enfrentadas en el debate, para después analizarlas desde un punto de vista pragmáticotranscendental que permita detectar sus fortalezas y debilidades, llegando a las siguientes conclusiones ${ }^{35}$ :

1) La fundamentación dogmática de carácter semiótico que, según Apel, permitió que se otorgara un alcance crítico-transcendental al hallazgo provisional e hipotético de un lenguaje ideal, o de una metafísica descriptiva de este tipo de supuestos semánticos, por ser un requisito exigido por cualquier descripción inductiva de un hecho de la experiencia, como al menos ocurrió en Quine, Searle y Strawson, al igual que anteriormente había ocurrido en Russell y el primer Wittgenstein. Hasta el punto que ahora estos presupuestos semióticos constituyen las condiciones mínimas de sentido que a su vez vienen exigidas desde un punto de vista critico-transcendental respecto de cualquier proyecto programático de investigación heurística y de comunicación intersubjetiva de naturaleza inductiva, aunque al menos en estos casos no se acabara de adoptar el punto de vista pragmático-transcendental que hubiera sido de desear ${ }^{36}$.

33 Apel, K. O.; Die Erklären:Verstehen-Kontroverse in transzendentalpragmatischer Sicht, Suhrkamp, Frankfurt, 1979.

34 Apel, K. O.; Transformation der Philosophie, Vol I.-II, Suhrmap, Franckfurt, 1973.

35 En este sentido Apel afirma: «Es precisamente entonces cuando se hace posible - a través de una observación unida a la lógica formal -, la necesidad específica de una conexión causal entre los acontecimientos cuya ulterior comprensión requiere a su vez la necesidad de de una prueba confirmativa de su validez inductiva «a largo plazo» (Peirce). (...) Y esto significa: que también Popper debe aceptar en última instancia la posibilidad de otorgar un fundamento pragmático-transcendental a la inducción)». Apel, K. O.; EVKTPS, p. 103-104. Böhler, D. ; Kettner, M.; Skirbekk, G.; Reflexion und Verantwortung: auseinandersetzungen mit Karl-Otto Apel, Suhrkamp, Frankfurt, 2003.

36 En este sentido Apel afirma: «Se puede contraponer la tesis holista de Quine con respecto 
2) Las sucesivas refundamentaciones meramente hipotéticas o revisionista que, según Apel, habría permitido que los seguidores del racionalismo crítico postpopperiano propugnaran un hipercriticismo aún más radicalizado, sin necesidad de remitirse ya a ningún tipo de presupuesto crítico-transcendental de carácter semiótico, por atribuirles una naturaleza convencional en sí misma falible, como propuso Bartley. De todos modos Apel hace notar como Popper siempre admitió la necesidad determinados presupuestos de tipo lógico o semiótico que quedarían fuera de este tipo de procesos de refutación y de consiguiente refundación por afirmarse como una condición de sentido de su propia puesta en práctica, como de hecho sucede con los primeros principios de la lógica, especialmente el de no contradicción, dado que no se pueden rechazar sin dar lugar a una contradicción pragmática entre lo que se dice y simultáneamente se hace en el correspondiente acto de habla ${ }^{37}$.

3) Las sucesivas refundaciones neodualistas o explicativo-comprensivas que, según Apel, habría permitido que la teoría de los juegos del lenguaje del segundo Wittgenstein fomentara un creciente meliorismo heurístico y semiótico, aunque sin tampoco poder evitar la aparición de un antifundamentalismo cada vez más contingente y relativista, como acabó sucediendo en Rorty. En cualquier caso ahora también se advierte que tampoco esta tercera estrategia de fundamentación adoptó un punto de vista pragmático-transcendental como el que, siguiendo a Peirce, hubiera sido de desear ${ }^{38}$.

V. El TRILEMA DEL NEODUALISMO POSTANALÍTICO ENTRE LAS TRES POSIBLES FORMAS DE (AUTO)-DETERMINACIÓN DEL SABER DISCURSIVO.

Por su parte Apel también denuncia la excesiva confianza que en estos casos se pone en unas estrategias de fundamentación claramente insuficientes, así como la manifiesta desconfianza que se adopta ante la ulterior aplicación de

a nuestra propuesta (...) de introducir una posible diferenciación - aún más radical - entre el «a priori» de la experiencia y el «a priori» de la reflexión. Esta sería precisamente la postura a defender desde una perspectiva pragmático-transcendental». Apel, K. O.; EVKTPS, p. 238. Cf. Kölbel, M.; Weiss, B. (eds); Wittgenstein's Lasting Significance, Routledge, London, 2004.

37 A este respecto Apel afirma: «Y esto significa: que también Popper debe aceptar en última instancia la posibilidad de otorgar un fundamento pragmático-transcendental a la inducción)». Apel, K. O.; EVKTPS, p. 103-104. Cf. Pauen, M.; Grundprobleme der Philosophie des Geistes. Eine Einführung, Fischer, Frannkfurt, 2001.

38 A este respecto Apel afirma: «La filosofía lingüística-analítica (...) se afirmó así como un tercer paradigma de la filosofía primera (...) que integra en sí - gracias a las mencionadas conquistas del neowittgenstenianismo - tanto las propuestas de la filosofía transcendental clásica, (...) como las conquistas metodológicas de una semiótica transcendental (....) de Peirce)». Apel, K. O.; EVKTPS, p. 328-331. Cf. Apel, K. O.; Paradigmen die Erste Philosophie, Surhkamp, Berlin, 2010. 
unas herramientas heurísticas y semióticas absolutamente necesarias, ya sea la inducción o la axiomatización. Prueba de ello es el uso tan desconcertante que von Wright hace de la noción de predeterminación y postdeterminación, a la que se podría sumar la noción de sobredeterminación. Se conciben ahora como tres posibles formas de (auto) determinación que puede alcanzar el saber práctico discursivo, especialmente si se tiene en cuenta el contexto posthegeliano donde Apel las sitúa. Sin embargo von Wright las concibe como si se trataran de unas nociones recíprocamente inconmensurables entre sí, sin poder hacer ya referencia a una similar base empírica de aplicación, dada la referencia temporal tan distinta desde las que en cada caso se formulan.

En efecto, von Wright formula la noción de predeterminación desde una teoría heurística de la explicación causal previamente ya dada y configurada, preferentemente orientada hacia el pasado. En cambio la noción de post-determinación se formula desde una teoría comprensiva respecto de una posible acción intencional futura con capacidad de lograr una mejor comprensión, aunque ello le exija tener que otorgar un carácter meramente hipotético a nuestras actuales formas de (auto) determinación. Finalmente, la sobredeterminación permitiría formalizar los distintos procesos explicativo-comprensivos que llevan a cabo en cada caso los diferentes juegos del lenguaje, orientándose preferentemente hacia la justificación de los subsiguientes procesos de racionalización de la actividad científica en presente, aunque de algún modo también puedan tener en cuenta el pasado y el futuro. En cualquier caso von Wright rechaza la posibilidad de justificar una recíproca conmensuración entre las tres anteriores formas de (auto) determinación del saber discursivo, al menos desde un punto de vista pragmático. Hasta el punto de tener que optar alternativamente por uno de ellos, preferentemente entre la predeterminación o la postdeterminación, pasado sucesivamente desde su inicial confirmación experimental dogmática de un determinado proceso de racionalización a su posterior revisión hipotética revisionista, o simplemente falsacionista, sin poder encontrar un punto medio entre ambas ${ }^{39}$.

En cambio Apel analiza estas tres posibles formas de (auto) determinación del saber discursivo desde un punto de vista pragmático-transcendental, comprobando la posibilidad de establecer una correlación entre los tres puntos de vista, sin considerarlos inconmensurables entre sí. En efecto, según Apel, la noción de predeterminación resulta operativa en los procesos de explicación causal dogmática del positivismo lógico, pero también se abre al futuro, desde que acepta la posibilidad de ser refutada mediante la simple comprobación de un hecho de la experiencia; en cambio la noción de post-determinación es el

39 Cf. Peter, F.; Schmid, H. B.; Rationality and Commiment, Oxford University, Oxford, 2007. 
resultado del modo racionalista crítico de concebir los futuros procesos de reformulación de una ley científica, aunque también están abiertos a la consideración del pasado, por cuando nada puede ser refutado si antes no hubiera sido dado por efectivamente verificado; finalmente, la noción de sobre-determinación vendría exigida por los procesos explicativo-comprensivos que a su vez acompañan al uso compartido de los juegos del lenguaje por ser un requisito de la justificación en presente de los distintos procesos de racionalización de la actividad científica, aunque también deben estar abiertos al pasado y al futuro, si pretenden evitar fomentar una absolutización o relativización abusiva ${ }^{40}$.

Evidentemente la diferencia entre Apel y von Wright reside en la posibilidad o no de justificar una posible conmensuración entre estas tres posibles formas de (auto) determinación del saber discursivo. En este sentido Apel recurre a un experimento mental muy concreto a la hora de mostrar la posibilidad de conmensurar recíprocamente entre sí estos distintos modelos nomológico deductivos o de cobertura legal, así como las correspondientes estrategias de fundamentación, según generen los consiguientes procesos de predeterminación experimental, de postdeterminación teleológica o de simple sobredeterminación funcional. Se trata del ejemplo al que recurrió Landesmann para justificar una posible conmensuración entre las distintas perspectivas desde las que la neurociencia formula sus valoraciones, según se adopte la postura del médico, del paciente o del interventor; del relator, del oponente o del juez; del investigador, del investigado o del fiscal; del encuestador, del encuestado o del empresario ${ }^{41}$.

En todos estos casos los diferentes participantes se remiten a diferentes juegos de lenguaje principales desde los que se valoran los resultados alcanzados, según adopten el punto de vista explicativo de la necesidad causal, comprensivo de la acción intencional teleológica o de la correlación explicativocomprensiva que en principio debería existir entre ambos. En cualquier caso Landesmann recurrió a este tipo de experimentos mentales para justificar los grandes postulados e ideales regulativos que a su vez están sobreentendidos en de un modo pragmático-transcendental a la hora de articular las distintas perspectivas explicativo-comprensivas que a su vez generan los distintos modelos nomológico-deductivos o de cobertura legal, así como las correspon-

40 A este respecto Apel afirma: «El neowittgenstianismo se vio obligado a tener que justificar una cada vez más completa disyunción entre los posibles juegos del lenguaje (... salvo que) pudiera estar vigente de un modo «a priori» esta nueva lógica de lo pragmáticotranscendental (...). Así fue como el «nuevo dualismo» postwittgenstteniano interpretó la situación de complementariedad pragmático-transcendental respecto de la verdad». Apel, K. O.; EVKTPS, p. 274. McManus, D.; The Enchantement of Words. Wittgenstein's Tractatus LogicoPhilosophicus, Clarendon, Oxford University., Oxford, 2006.

41 Boghosian, P.; El miedo al conocimiento. Contra el relativismo y el constructivismo, Alianza, Madrid, 2009. 
dientes estrategias de fundamentación, por tratarse de un presupuesto que a su vez viene exigido por estos mismos procesos de creciente racionalización de la naturaleza. Hasta el punto que si ya no se admiten estos ideales de alcance pragmático-transcendental tampoco se hubiera podido justificar la posterior aplicación a la neurociencia o a cualquier otro saber, de una teoría de los juegos del lenguaje, donde se presupone desde un principio esta creciente capacidad de intercomunicación y de conmensuración recíproca existente entre los distintos agentes sociales ${ }^{42}$.

\section{CONCLUSIÓN: ¿FOMENTÓ EL DEBATE EXPLICACIÓN-COMPRENSIÓN UNA INNECESARIA RADICALIZACIÓN DEL ANTI-FUNDAMENTALISMO?}

Evidentemente el debate explicación-comprensión tuvo un especial impacto en el reconocimiento del carácter explícitamente positivista-lógico, racionalista-crítico, o simplemente neodualista heurístico, que Russell, el primer Wittgenstein, Popper o el segundo Wittgenstein, atribuyeron a sus respectivas propuestas metodológicas. En cualquier caso para llegar a estas conclusiones finales estos autores también tuvieron que recurrir a distintos procedimientos de determinación, o mas bien (auto) determinación, mediante diversas estrategias de tipo pre-, post- o sobre-determinación, de los correspondientes saberes prácticos discursivos. Sin embargo al hacer estas propuestas tampoco se pudo evitar la aparición de una crisis cada vez más generalizada de los respectivos modelos nomológico deductivos o de cobertura legal, salvo que se acepte una fundamentación pragmático-transcendental, a pesar de acabar siendo muy polémica ${ }^{43}$.

En cualquier caso, a raíz de la muerte de Wittgenstein en 1953, no sólo se divulgó su posterior teoría de los juegos del lenguaje, sino que también se exigió que el neodualismo postanalítico abordara otros tres debates ulteriores complementarios, a saber: el debate acerca de la autoinmunidad sobrevenida, el debate sobre el ficcionalismo oracular, así como el ulterior movimiento de rehabilitación del silogismo práctico que, ya fuera de tipo neoaristotélico o posthegeliano, sería llevado a cabo por Anscombe y Gadamer respectivamente.

42 A este respecto Apel afirma: «En estos casos es evidente que ambos psicólogos ya no examinan al otro como un componente de la comunidad de comunicación de los investigadores, sino como un simple objeto de la ciencia (... de modo que) que cada uno por separado, (... debe) recurrir a una diferente comunidad de comunicación mediante el correspondiente juego del lenguaje de la comprensión» (...) a fin de reestablecer la correspondiente situación de complementariedad». Apel, K. O.; EVKTPS, p. 275; Cf. Landesmann, Ch.; "The New Dualism in the Philosophy of the Mind", Rev. of Metaph, 19, 1965/66, 329-349 pp.

43 Ortiz de Landázuri, C.; La autoinmunidad sobrevenida del neodualismo postanalítico. (A través de von Wright y Apel), sin publicar. Cf. Searle, John R.; Philosophy in a New Century. Selected Essays, Cambridge University, Cambridge, 2008. 
De todos modos reconstruir el impacto que tuvieron estas últimas propuestas del segundo Wittgenstein en la génesis de estos posteriores debates es una cuestión muy compleja y habrá que dejarla para otro momento ${ }^{44}$.

Carlos Ortiz de Landázuri es Catedrático de Instituto de Enseñazas Medias desde 1976 (Jubilado). Profesor visitante de la Universidad de Navarra en la asignatura de Historia y Metodología de la Ciencia desde el curso 1976/77. (Jubilado).

Líneas de investigación:

Tesis doctoral en 1885 en la Universidad de Navarra sobre 'Acción y método en la transformación de la filosofía de Karl-Otto Apel'.

Publicaciones diversas sobre teoría del arte, especialmente Gombrich, una vida entre Wittgenstein y Popper, en los Cuadernos de la Cátedra Felix Huarte, nº 6 y 7.

Diversos artículos en Anuario Filosófico sobre Wittgenstein y Heidegger.

Numerosos artículos y reseñas de libros en Anuario Filosófico, Teorema, Theoria, Educación y sociedad, Acta Philosófica, Diálogo Filosófico, Paideia.

Últimas publicaciones:

(2012) 'La lógica barroca de Salvador Izquierdo. A propósito de la doble cuantificación de la proposición', en Murillo, I. (ed.); El barroco iberoamericano y la modernidad, Universidad Pontificia de Salamanca, Congreso de la UPSA- Dialogo Filosófico, Salamanca, 187-195 pp.

(2013) ‘CCulminó Zubiri el giro personalista de su filosofía primera? Reconstrucción de un debate (A través de Gracia, San Baldomero, Corominas y Pintor Ramos)', en Revista Endoxa, UNED, n $31,145-189$ pp..

Dirección de correo: cortiz@unav.es

44 Ortiz de Landázuri, C.; El ficcionalismo oracular del neodualismo postanalítico. (A través de von Wright y Apel), sin publicar. Cf. Popper, K.; Bosetti, G. (interview); Lesson of this Century. With Two Talks on Freedom and the Democratic State, Routledge, London, 2000. 
